\title{
Cross-task strategic effects
}

\author{
KATHLEEN RASTLE \\ Royal Holloway, University of London, Egham, England \\ and Macquarie University, Sydney, Australia \\ SACHIKO KINOSHITA \\ Macquarie University, Sydney, Australia \\ STEPHEN J. LUPKER \\ University of Western Ontario, London, Ontario, Canada \\ and Macquarie University, Sydney, Australia \\ and \\ MAX COLTHEART \\ Macquarie University, Sydney, Australia
}

\begin{abstract}
When easy and difficult items are mixed together, their reading aloud latencies become more homogeneous relative to their presentation in unmixed ("pure") conditions (Lupker, Brown, \& Colombo, 1997). We report two experiments designed to investigate the nature of the mechanism that underlies this list composition, or blocking, effect. In Experiment 1, we replicated Lupker et al.'s (1997) blocking effect in the reading aloud task and extended these findings to the visual lexical decision task. In Experiment 2, we found that blocking effects generalized across tasks: The characteristics of stimuli in a visual lexical decision task influenced reading aloud latencies, and vice versa, when visual lexical decision and reading aloud trials were presented alternately in the same experiment. We discuss implications of these results within time-criterion (Lupker et al., 1997) and strength-of-processing (Kello $\&$ Plaut, 2000, 2003) theories of strategic processing in reading.
\end{abstract}

When one is recognizing or reading a word aloud, one's performance will be affected both by aspects of the stimulus (e.g., frequency, neighborhood size) and by factors that are extraneous to the stimulus, factors that can induce various strategies. Strategic influences on performance can be very deliberate-for example, when a participant seeks to perform with a great deal of accuracy-but they can also be subtler. In this article, we consider one of these subtler influences on reading aloud: the list composition, or blocking, effect.

Over the past 6 years, Lupker and colleagues have shown repeatedly that the time taken to read aloud a target stimulus is influenced by the characteristics of the other items in the experiment (Lupker, Brown, \& Colombo, 1997; Lupker, Kinoshita, Coltheart, \& Taylor, 2000; Taylor \& Lupker, 2001). Specifically, when stimuli with different mean latencies are mixed together, their mean latencies become more homogeneous: "Fast" stimuli become slower, and "slow" stimuli become faster, relative to pre-

We are grateful to Anna Woollams and Judy Wilson for research assistance and to Marc Brysbaert, Tom Carr, Ken Forster, Chris Kello, Peter Kwantes, Jay Rueckl, and Greg Simpson for valuable comments on an earlier version of this manuscript. Correspondence may be addressed to K. Rastle, Department of Psychology, Royal Holloway, University of London, Egham, Surrey, TW20 OEX UK (e-mail: kathy.rastle@ rhul.ac.uk). sentation in pure blocks of items. Although these blocking effects are viewed across whole blocks of stimuli, they may arise at the level of single trials, as is evidenced by the trial-by-trial sequence effects reported by Taylor and Lupker (2001). In this article, we consider the generality of these blocking effects, seeking to pose constraints on theorizing about the mechanism that underlies them.

\section{What Blocking Effects on Reading Aloud Are Not}

Route-emphasis effects. Interest in blocking effects on reading aloud developed initially because of their apparent relevance to the architecture of the reading system, particularly in relation to the debate between dual-route theorists (e.g., Coltheart, 1978) and single-route analogy theorists (e.g., Glushko, 1979; see Humphreys \& Evett, 1985, for a review of this controversy). If the architecture of the reading system comprised two processing routines-one lexical and one nonlexical - then it might be possible to vary consciously or unconsciously the extent to which each is used, depending on the requirements of the reading situation. A situation in which a reader is presented with a list of words with spelling-sound exceptions (e.g., CHEF) might result in a decreased reliance on nonlexical processing, since such processing would result in an incorrect response on every trial. In many cases, this route-emphasis mechanism predicts exactly the types of reaction time (RT) homoge- 
nization effects observed by, for example, Lupker et al. (1997) and Taylor and Lupker (2001; see also Monsell, Patterson, Graham, Hughes, \& Milroy, 1992; Rastle \& Coltheart, 1999).

Irrespective of whether route emphasis can be strategically altered (Kinoshita \& Lupker, 2002; Zevin \& Balota, 2000), it seems likely that the blocking effects observed by Lupker and colleagues reflect a mechanism quite different from a route emphasis one. For one, RT homogenization effects have been shown to occur in situations in which route emphasis would not be appropriate-for example, when mixed blocks of high- and low-frequency irregular words are read aloud (Lupker et al., 1997, Experiment 3; see also Chateau \& Lupker, 2003). Furthermore, it appears that this pattern of blocking effect arises in a number of other speech production domains. Lupker et al. (2000) have reported the RT homogenization effect in reading aloud, picture naming, and sum naming. Furthermore, they have observed blocking effects across input domains, in situations in which picture naming, sum naming, and reading aloud trials are mixed within a single experiment. Given the generality of the blocking effect, it seems unlikely that this strategic effect is specific to the procedures used in the translation of orthography to phonology.

Mixing-cost effects. It is crucially important not to confuse these blocking effects on reading aloud with the mixing-cost effects that arise when stimuli of different perceptual categories (e.g., intact and degraded) are mixed together. Some research (see Los, 1996, 1999, for excellent reviews) has shown that when two levels of a perceptual variable (e.g., stimulus quality) are mixed, performance is disadvantaged for both levels relative to performance in pure blocks of each level (although this disadvantage can be asymmetric-i.e., the cost can be greater for the level of the variable responded to faster in pure blocks-Los, 1999). Mechanisms proposed to underlie this mixing-cost effect are similar to those discussed in the task-switching literature (e.g., Rogers \& Monsell, 1995): The idea is that mixing two levels of a perceptual variable in a single experiment leads to disadvantaged performance because of an increase in mental load (i.e., keeping two tasks prepared) and/or a switch between computationally different processes (see, e.g., Los, 1999; Merian, 2000).

Although we appreciate that mixing costs as well as taskswitching costs are found in the performance literature, the situation that we describe here-denoted by the more neutral term of blocking effects-is quite different empirically and theoretically. Empirically, blocking effects on reading aloud involve a mixing cost only for one level of the independent variable: Whereas mixing slows responses to easy stimuli (e.g., high-frequency words), it speeds responses to hard stimuli (e.g., low-frequency words). Theoretically, it is difficult to reconcile a switch-cost mechanism with the types of variables that have been manipulated in the blocking literature on reading aloud (e.g., word frequency). According to the current computational models of reading (e.g., Coltheart, Rastle, Perry, Langdon, \& Ziegler, 2001; Plaut, McClelland, Seidenberg, \& Patterson, 1996), the processing requirements for reading high-frequency and low-frequency words, for example, are qualitatively identical. Moreover, even a situation in which words and nonwords are mixed would not necessarily entail a switch in computational requirements: Coltheart et al.'s (2001) dualroute cascaded (DRC) model processes words and nonwords within the same two processing routines without any parametric variation; similarly, in Plaut et al.'s (1996) parallel distributed processing model, words and nonwords are processed within a single procedure, again without parametric variation. For these reasons, we believe that the blocking effects investigated here can best be treated outside of the mixing-cost literature.

\section{A Time-Criterion Approach to Blocking Effects}

Accordingly, Lupker and colleagues (Lupker et al., 1997; Taylor \& Lupker, 2001) have conceptualized these effects as arising due to the operation of adjustable thresholds that control information flow from phonological to articulatory levels of processing. Specifically, they have argued that a time criterion plays a role in determining when information is passed from the phonological system to the articulatory system (Taylor \& Lupker, 2001). Simply put, subjects have an expectation of when they should be responding based on their experience with other stimuli in the trial block (or the item immediately preceding the target) and perform accordingly. The time criterion is flexible: It is set on the basis of the average difficulty of the stimuli in the experiment (or, indeed, the difficulty of the item immediately preceding the target). When all of the items are easy, subjects adopt a shorter value for the time criterion. When all of the items are difficult, subjects adopt a longer value for the time criterion. In mixed blocks of stimuli, only one value of the time criterion can be adopted, and there is a homogenization of RTs.

Although Lupker et al. (1997) referred to their time criterion as a "deadline" for responding (p. 582), Taylor and Lupker (2001) recognized that this could not be a sufficient account of their observed effects. They wrote, "... although the criterion placement guides responding, it does not dictate it" (p. 130), for the reason that in mixed blocks of stimuli, significant effects of stimulus type still emerge (e.g., in mixed blocks of high-frequency and lowfrequency irregular words, a frequency effect is still observed-Lupker et al., 1997; see also Kello \& Plaut, 2000). Taylor and Lupker therefore speculated that information flow from phonological to articulatory levels of processing might be controlled by some combination of a time criterion and a quality criterion (based on the quality of the phonological code). They speculated that information might be passed between these levels of processing prior to the time criterion if a phonological code of sufficiently high quality had been developed before that time, or delayed beyond the criterial time if the level of code quality that had been reached at that time was still dangerously low. Critically, Taylor and Lupker have conceptualized the time-quality criterion as a mechanism particular to the processes involved in naming. 


\section{Blocking Effects in Non-naming Tasks}

There is some evidence, however, to suggest that similar RT homogenization effects also arise within tasks that do not engage speech production components of the language system. For example, Strayer and Kramer (1994a, 1994b) reported blocking effects on memory search when consistent mapping and varied mapping trials were presented in pure and mixed blocks of items. Furthermore, the effect of word frequency on visual lexical decision is smaller when high- and low-frequency words are presented in mixed blocks than when they are presented in pure blocks (Glanzer \& Ehrenreich, 1979; Gordon, 1983). ${ }^{1}$ It is possible, of course, that blocking effects will arise in a range of performance tasks, at different functional levels within each of those tasks. The question is, however, whether the blocking effects across these disparate tasks engage a common mechanism. Should we be looking for a more general theory, not specific to the relation between phonology and articulation, to account for the blocking effects on reading aloud?

If blocking effects arise at a stage of processing common to all of these disparate tasks, then we may expect blocking effects to arise across output tasks when these tasks are presented alternately in a single experiment (provided that task-switching costs have been controlled). The performance on one output task (for example, reading aloud) will influence and be influenced by the performance on a completely different output task (for example, visual lexical decision). For example, responses on reading aloud trials will be faster when items are presented in alternation with easy visual lexical decision trials than when presented in alternation with hard visual lexical decision trials. Cross-task blocking effects may implicate (1) a system whereby performance is monitored irrespective of task and (2) a single strategically tuned control mechanism that affects performance on both tasks. Note here that we are not interested in whether task alternation itself induces a performance disadvantage; we are interested in examining whether RT homogenization effects will be revealed over and above any across-the-board task-switching cost.

We conducted two experiments in order to examine this prediction. In Experiment 1, we confirmed that blocking effects arise within reading aloud and visual lexical decision tasks, using the stimuli to be used in the cross-task situation. In Experiment 2, we examined whether these blocking effects arise across reading aloud and visual lexical decision tasks when these tasks are presented alternately in the same experiment - thus raising the possibility that a control mechanism (perhaps a time-quality criterion) operates at a stage of processing common to both output tasks.

\section{EXPERIMENT 1}

Experiments 1A and 1B were conducted to confirm that the test stimuli to be used in the cross-task experiment show blocking effects within a single task (i.e., when the task is not mixed with a different task). In Experiment 1 A, we used a reading aloud task, and in Experiment 1B we used a visual lexical decision task. In both tasks, there was a pure block of easy items, a pure block of hard items, and a mixed block. In the lexical decision task, the easy manipulation versus the hard manipulation involved changing both the words and the nonwords. On the basis of previous findings, we expected to observe an RT homogenization effect in the mixed-block situations for both the reading aloud responses (Experiment 1A) and the "yes" responses of the visual lexical decision task. We are unaware of any research into effects of RT homogenization on the "no" responses in the visual lexical decision task, and we were therefore uncertain whether such effects would be revealed.

\section{EXPERIMENT 1A Reading Aloud Task}

\section{Method}

Participants. Twenty-four Macquarie University students participated voluntarily in Experiments $1 \mathrm{~A}$ and $1 \mathrm{~B}$ for course credit. All the participants were native Australian-English speakers. Half of the participants completed the reading aloud task (Experiment 1A) first; the other half completed the visual lexical decision task (Experiment 1B) first.

Design. Experiment $1 \mathrm{~A}$ constituted a 2 (block type: pure vs. mixed) $\times$ 2 (item difficulty: easy vs. hard) factorial design, with both factors manipulated within participants. The participants read aloud stimuli in three blocks: pure easy, pure hard, and mixed. The dependent variables were reading aloud latency and error rate.

Materials. The test stimuli were 80 "easy-to-read" (hereafter, easy) items and 80 "hard-to-read" (hereafter, hard) items. All items were five letters in length. The easy items were high-frequency words (minimum frequency 600 occurrences per 17.9 million, based on the CELEX corpus; Baayen, Piepenbrock, \& van Rijn, 1993), which comprised regular grapheme-phoneme correspondences (as defined by Coltheart et al.'s, 2001, DRC model of reading; e.g., beach, drink, and horse). Hard items were nonwords with no orthographic neighbors (e.g., bluce, crarc, and drith), selected from the ARC Nonword Database (Rastle, Harrington, \& Coltheart, 2002). The stimuli are listed in the Appendix.

The easy and hard items were divided into two sets containing 40 items each, Sets A and B, matched on their onset phonemes (i.e., all consonant phonemes preceding the vowel). Two list versions were constructed for the purpose of counterbalancing assignment of sets to block type. Version 1 contained a pure block of Set A easy items, a pure block of Set A hard items, and a mixed block of Set B easy items and Set B hard items. Version 2 contained a pure block of Set B easy items, a pure block of Set B hard items, and a mixed block of Set A easy items and Set A hard items.

Prior to each test block, the participants were given several practice items ( 4 in pure blocks, 8 in mixed blocks). Furthermore, each test block was initiated with a number of warm-up items (6 in each of the pure blocks and 12 in the mixed block), which were discarded from the analysis. The warm-up and practice items were similar to the test stimuli, except that they were four letters long.

Apparatus and Procedure. The participants were tested individually. They were seated approximately $40 \mathrm{~cm}$ in front of an NEC Multisync 4FG monitor, on which the stimuli were presented. Each participant completed three blocks of trials- one mixed block and two pure blocks - with the mixed block containing twice as many stimuli as each pure block. Half of the participants completed the mixed block first; the other half completed the pure blocks first. Furthermore, the order of pure blocks was counterbalanced across participants. Finally, half of the participants received Version 1 of the stim- 
ulus lists; the other half received Version 2. Full counterbalancing of order and version was, therefore, realized with every 8 participants.

At the outset of the experiment, the participants were told that a list of letter strings would be shown on the computer screen, one at a time. The participants were instructed to read aloud the letter strings as quickly and as accurately as possible.

Stimulus presentation and data collection were achieved through the use of the DMASTR display system developed by K. I. Forster and J. C. Forster at the University of Arizona (see http://www.u. arizona.edu/ kforster/dmastr/dmastr.htm) running on a Deltacom 486 personal computer. RTs were recorded using a voice key that triggered when a criterial level of amplitude was reached. The voice key was calibrated for each participant prior to the experiment and was not recalibrated at any time during the testing session. ${ }^{2}$ The voice key was fitted to each participant by means of a headset, such that it was held at a constant distance from the mouth throughout the experiment. Reading aloud errors and possible measurement errors due to inappropriate voice key activation were recorded manually by the experimenter.

Each trial started with the presentation of a target letter string, presented in lowercase letters in Triplex font, centered in the bottom half of the screen. The letter string remained on the screen for a maximum of 2,000 msec, or until the voice key was triggered by the participant's response. Following a blank screen of $800 \mathrm{msec}$, the next trial started. The participants were given no feedback on either reading aloud latencies or error rates during the experiment.

\section{Results}

For this and subsequent analyses, data were cleaned so as to exclude any trial on which a participant error or voice key error occurred; remaining RT data were winsorized to the second standard deviation boundary. Two-way analyses of variance (ANOVAs) were conducted, both by subjects and by items, with block type (pure vs. mixed) and item difficulty (easy vs. hard) as factors. In the by-participants analysis, both factors were treated as repeated; in the byitems analysis, block type was treated as a repeated factor and item difficulty was treated as an unrepeated factor. Effects reported as significant were significant at the .05 level. Mean naming latencies and error rates from the byparticipants analysis are presented in Table 1 .

The expected interaction between block type and item difficulty was revealed in the analysis of the RT data $\left[F_{1}(1,23)=41.22, M S_{\mathrm{e}}=392.92 ; F_{2}(1,158)=68.83\right.$, $\left.M S_{\mathrm{e}}=878.21\right]$, such that the effect of item difficulty was reduced but not eliminated $\left[t_{1}(23)=8.58, t_{2}(158)=\right.$ 14.72] in the mixed block relative to the pure blocks. In the presence of this interaction, main effects comparisons are not reported.

In the analysis of errors, the main effect of item difficulty was significant by subjects and by items $\left[F_{1}(1,23)=\right.$ $\left.16.38, M S_{\mathrm{e}}=91.80 ; F_{2}(1,158)=60.41, M S_{\mathrm{e}}=83.02\right]$.

Table 1

Mean Reading Aloud Latencies (RT, in Milliseconds) and Percent Error Rates (\% E) in Experiment $1 \mathrm{~A}$

\begin{tabular}{|c|c|c|c|c|c|c|}
\hline \multirow[b]{3}{*}{ Block Type } & \multicolumn{4}{|c|}{ Item Difficulty } & & \\
\hline & \multicolumn{2}{|c|}{ Easy } & \multicolumn{2}{|c|}{ Hard } & \multicolumn{2}{|c|}{ Difference } \\
\hline & RT & $\% \mathrm{E}$ & RT & $\% \mathrm{E}$ & RT & $\% \mathrm{E}$ \\
\hline Pure & 448 & 2.0 & 578 & 9.1 & 130 & 7.1 \\
\hline Mixed & 460 & 2.5 & 538 & 11.3 & 78 & 8.8 \\
\hline Difference & 12 & 0.5 & -40 & 2.2 & & \\
\hline
\end{tabular}

The main effect of block type failed to reach significance by subjects $\left[F_{1}(1,23)=3.91, M S_{\mathrm{e}}=11.27\right]$ but was significant by items $\left[F_{2}(1,158)=4.02, M S_{\mathrm{e}}=36.50\right]$, and the interaction between these two effects was not significant $\left[F_{1}(1,23)=1.12, M S_{\mathrm{e}}=14.90 ; F_{2}(1,158)=1.52\right.$, $\left.M S_{\mathrm{e}}=36.50\right]$.

\section{EXPERIMENT 1B Visual Lexical Decision Task}

\section{Method}

Participants. The participants used in Experiment 1A were also used in Experiment 1B.

Design. Experiment 1B constituted a 2 (block type: pure vs. mixed) $\times 2$ (item difficulty: easy vs. hard) factorial design, with both factors manipulated within participants. The participants performed lexical decisions in three blocks: pure easy, pure hard, and mixed. The dependent variables were lexical decision latency and error rate.

Materials. The test stimuli were 40 easy words, 40 hard words, 40 easy nonwords, and 40 hard nonwords. All items were four letters long. The easy words were high in frequency (CELEX frequency range of 2,008-192,247 occurrences per 17.9 million) and had 8-23 neighbors (e.g., game, book, full). The hard words were low in frequency (CELEX frequency range of 11-197 occurrences per 17.9 million) and had 0-4 neighbors (e.g., gnat, fret, lisp). Nonwords were selected from the ARC Nonword Database (Rastle et al., 2002). Easy nonwords had no orthographic neighbors (e.g., sesc, kuiv, $c e e b$ ); hard nonwords had a minimum of 13 orthographic neighbors with existing bodies (e.g., gake, selt, dack). The stimuli are listed in the Appendix.

Apparatus and Procedure. The apparatus was identical to that used in Experiment 1A, except that a two-button response pad was used to collect responses instead of a voice key. The "yes" response button was controlled by the dominant hand. The participants were advised that they would be seeing a series of letter strings presented one at a time and that they would be required to decide as quickly and as accurately as possible whether or not each letter string was a word, indicating their decisions via the response pad. The timing parameters on each trial were the same as those in Experiment 1A, except that the target letter string was presented in the top half of the screen and was flanked by plus and minus signs for consistency with Experiment 2. The counterbalancing of stimuli to blocks and of block order was identical to that in Experiment $1 \mathrm{~A}$.

\section{Results}

Lexical decision latency and error rate were analyzed using a 2 (block type: pure vs. mixed) $\times 2$ (item difficulty: easy vs. hard) ANOVA, separately for words and nonwords. In the by-participants analysis, both factors were treated as repeated; in the by-items analysis, block type was treated as a repeated factor and item difficulty was treated as an unrepeated factor. Data from the by-participants analysis are presented in Table 2 .

Words. In the RT analysis, the expected interaction between block type and item difficulty was observed $\left[F_{1}(1,23)=\right.$ $\left.15.13, M S_{\mathrm{e}}=1,215.76 ; F_{2}(1,78)=26.12, M S_{\mathrm{e}}=1,548.41\right]$, such that the effect of item difficulty was reduced but not eliminated $\left[t_{1}(23)=10.48, t_{2}(78)=10.27\right]$ in the mixed blocks relative to the pure blocks. In the presence of this interaction, main effects comparisons are not reported.

The interaction between block type and item difficulty was also observed in the error data $\left[F_{1}(1,23)=6.37\right.$, $\left.M S_{\mathrm{e}}=47.24 ; F_{2}(1,78)=8.57, M S_{\mathrm{e}}=58.57\right]$. It should be 
Table 2

Mean Lexical Decision Latencies (RT, in Milliseconds) and Percent Error Rates (\%E) in Experiment 1B

\begin{tabular}{|c|c|c|c|c|c|c|}
\hline \multirow[b]{3}{*}{ Block Type } & \multicolumn{4}{|c|}{ Item Difficulty } & & \\
\hline & \multicolumn{2}{|c|}{ Easy } & \multicolumn{2}{|c|}{ Hard } & \multicolumn{2}{|c|}{ Difference } \\
\hline & RT & $\% \mathrm{E}$ & RT & $\% \mathrm{E}$ & RT & $\% \mathrm{E}$ \\
\hline \multicolumn{7}{|l|}{ Words } \\
\hline Pure & 446 & 4.4 & 602 & 17.7 & 156 & 13.3 \\
\hline Mixed & 483 & 2.7 & 583 & 23.1 & 100 & 20.4 \\
\hline Difference & 37 & -1.7 & -19 & 5.4 & & \\
\hline \multicolumn{7}{|l|}{ Nonwords } \\
\hline Pure & 499 & 3.5 & 645 & 11.0 & 146 & 7.5 \\
\hline Mixed & 534 & 3.8 & 626 & 16.3 & 92 & 12.5 \\
\hline Difference & 35 & 0.3 & -19 & 5.3 & & \\
\hline
\end{tabular}

noted that the pattern of this interaction is opposite to that of the latency data: The item difficulty effect is magnified in the mixed block relative to the pure blocks, indicating a speed-accuracy tradeoff. In the presence of this interaction, main effects comparisons on error rate are not reported.

Nonwords. As was the case for the "yes" responses, an interaction between block type and item difficulty was observed on the RT data $\left[F_{1}(1,23)=11.58, M S_{\mathrm{e}}=1,518.31\right.$; $\left.F_{2}(1,78)=14.84, M S_{\mathrm{e}}=1,757.78\right]$, such that the effect of item difficulty was reduced but not eliminated $\left[t_{1}(23)=\right.$ $\left.9.43, t_{2}(78)=10.66\right]$ in mixed blocks relative to pure blocks. Main effects comparisons are not reported in the presence of this interaction.

In the analysis of errors, the main effect of block type was not significant by subjects $\left[F_{1}(1,23)=2.87, M S_{\mathrm{e}}=\right.$ $61.37]$ but was significant by items $\left[F_{2}(1,78)=4.85, M S_{\mathrm{e}}=\right.$ 60.68]. The main effect of item difficulty was again significant $\left[F_{1}(1,23)=23.37, M S_{\mathrm{e}}=102.72 ; F_{2}(1,78)=52.23\right.$, $\left.M S_{\mathrm{e}}=76.64\right]$. The interaction between these effects was not significant by subjects $\left[F_{1}(1,23)=2.79, M S_{\mathrm{e}}=53.80\right]$, but was significantby items $\left[F_{2}(1,78)=4.15, M S_{\mathrm{e}}=60.68\right]$.

\section{Discussion of Experiment 1}

The results of Experiment 1 are clear if perhaps unsurprising. With these particular stimuli and task parameters, blocking effects were observed in both the reading aloud task and the visual lexical decision task, such that latencies became more homogenous in the mixed block situations relative to the pure block situations: RTs to easy items became longer and RTs to hard items became shorter in mixed blocks. Experiment 1 serves as a reminder that responding in both of these tasks is not governed by stimulus factors alone: Indeed, responding is also controlled by the properties of other stimuli in the environment. In Experiment 2, we sought to determine whether these blocking effects extend to cross-task situations within a single experimentthat is, whether the characteristics of lexical decision items can influence reading aloud latencies and vice versa.

\section{EXPERIMENT 2}

Experiments 1A and 1B demonstrated that the stimuli and task parameters used produced blocking effects in both the reading aloud task and the visual lexical decision task. In Experiment 2, we used the same stimuli and task parameters to test whether each task would show sensitivity to the difficulty of the other task when the tasks were mixed within a block - that is, whether the blocking effect generalizes across different tasks. Experiment 2 constitutes a task-switching situation: Within each block, trials alternated between reading aloud and visual lexical decision tasks. Although we would therefore expect a taskswitching cost to characterize the participants' performance, that task-switching cost will apply to every trial block of the experiment. The effects that interest us here-whether reading aloud latency is affected by the difficulty of lexical decision trials, and whether lexical decision latency is affected by the difficulty of the reading aloud trials - are assumed to emerge on top of the likely switch cost characteristic of the alternating-task situation (and cannot be due to the special demands posed by switching between tasks).

\section{Method}

Participants. Thirty-two Macquarie University students voluntarily participated in the experiment for course credit. All the participants were native speakers of Australian-English and had normal or corrected-to-normal vision.

Design. Each participant was presented with four blocks of stimuli, within which reading aloud and visual lexical decision trials alternated. These four trial blocks resulted from a factorial combination of two variables: reading aloud difficulty (easy vs. hard) and lexical decision difficulty (easy vs. hard). We treated the difficulty of target-task trials and the difficulty of filler-task trials as independent variables (in the analysis of reading aloud responses, reading aloud is the target task and lexical decision is the filler task; in the analysis of lexical decision responses, lexical decision is the target task and reading aloud is the filler task). We expected main effects of target task difficulty (indicating that hard items produce slower responses than easy items) and filler task difficulty (indicating that hard filler items slow target responding relative to easy filler items), but no interaction between these factors (indicating that easy and hard target items are affected equivalently by the filler manipulation). ${ }^{3} \mathrm{RT}$ and error rate for each of the three measures (reading aloud, the "yes" response, and the "no" response) served as dependent variables.

Materials. The target stimuli used in this experiment were identical to those used in Experiments 1A and 1B. Each participant was presented with four blocks of trials, each block consisting of 40 reading aloud trials and 40 lexical decision trials ( 20 words and 20 nonwords). Each block represented one condition resulting from a factorial combination of easy or hard reading aloud items and easy or hard lexical decision items. As in Experiments 1A and 1B, test stimuli within each task (reading aloud and lexical decision) and within each difficulty class (easy and hard) were divided into two sets (Set A and Set B) for counterbalancing purposes. Sets of items used in the reading aloud task were matched on onset phonemes.

Apparatus and Procedure. The apparatus and general procedure were identical to those of Experiments $1 \mathrm{~A}$ and 1B. The participants were advised that they would be presented with letter strings alternating consistently between the bottom and top halves of the screen, to which the participants were to respond by reading aloud and making a lexical decision, respectively. Items for lexical decision, appearing in the top half of the screen, were flanked by plus and minus signs, as in Experiment 1B. The order of easy and hard blocks (within reading aloud and lexical decision tasks), and the assignment of sets of items to the blocks were counterbalanced across participants so that 16 participants were required for a full counterbalancing. 


\section{Results}

Latency and error data were collected and cleaned using the procedures described in Experiment 1A. RT and error data from each task were submitted to 2 (target task difficulty) $\times 2$ (filler task difficulty) ANOVAs. In the byparticipants analysis, both factors were treated as repeated; in the by-items analysis, target task difficulty was treated as an unrepeated factor, whereas filler task difficulty was treated as a repeated factor. Mean RT and error data for the reading aloud task based on the by-participants analysis are shown in Table 3; RT and error data for the lexical decision task based on the by-participants analysis are shown in Table 4.

Reading aloud. As was predicted, in the analysis of RTs, the ANOVA revealed significant main effects of both target task difficulty $\left[F_{1}(1,31)=107.47, M S_{\mathrm{e}}=5,573.46\right.$; $\left.F_{2}(1,158)=427.84, M S_{\mathrm{e}}=3,564.18\right]$, and filler task (lexical decision) difficulty $\left[F_{1}(1,31)=11.32, M S_{\mathrm{e}}=1,191.98\right.$; $\left.F_{2}(1,158)=50.01, M S_{\mathrm{e}}=643.09\right]$. These findings indicate that the speed of reading aloud responses is governed both by the characteristics of the reading aloud stimuli themselves and by the characteristics of the lexical decision stimuli in the experiment. The interaction between these two effects was not significant by participants $\left[F_{1}(1,31)=2.06, M S_{\mathrm{e}}=655.14\right]$ but was significant by items $\left[F_{2}(1,158)=4.88, M S_{\mathrm{e}}=643.09\right]$.

In the analysis of errors, the main effect of target task difficulty was significant $\left[F_{1}(1,31)=26.41, M S_{\mathrm{e}}=7.81\right.$; $\left.F_{2}(1,158)=30.16, M S_{\mathrm{e}}=0.43\right]$, but the main effect of filler task difficulty was not significant $\left[F_{1}(1,31)<1.0 ; F_{2}(1,158)<\right.$ 1.0]. The two effects did not interact $\left[F_{1}(1,31)<1.0\right.$; $\left.F_{2}(1,158)<1.0\right]$.

Lexical decision: "yes" response. In the analysis of RTs, the ANOVA again revealed significant main effects of both target task difficulty $\left[F_{1}(1,31)=239.90, M S_{\mathrm{e}}=\right.$ $\left.3,149.41 ; F_{2}(1,78)=342.18, M S_{\mathrm{e}}=2,882.36\right]$ and filler task (reading aloud) difficulty $\left[F_{1}(1,31)=9.43, M S_{\mathrm{e}}=\right.$ $\left.2,321.78 ; F_{2}(1,78)=11.10, M S_{\mathrm{e}}=2,739.05\right]$. These two effects did not interact $\left[F_{1}(1,31)<1.0 ; F_{2}(1,78)<1.0\right]$. Like the speed of the reading aloud responses, the speed of the "yes" responses in lexical decision was governed both by the characteristics of the lexical decision items and by the characteristics of the reading aloud items.

In the analysis of errors, the main effect of target task difficulty was significant $\left[F_{1}(1,31)=49.37, M S_{\mathrm{e}}=\right.$ $\left.112.99 ; F_{2}(1,78)=35.88, M S_{\mathrm{e}}=4.98\right]$, but the main effect of filler task difficulty was not significant $\left[F_{1}(1,31)<\right.$ $\left.1.0 ; F_{2}(1,78)<1.0\right]$. The interaction effect was also nonsignificant $\left[F_{1}(1,31)<1.0 ; F_{2}(1,78)<1.0\right]$.

Table 3

Mean Reading Aloud Latencies (RTs, in Milliseconds) and Percent Error Rates (\% E) in Experiment 2

\begin{tabular}{|c|c|c|c|c|c|c|}
\hline \multirow[b]{3}{*}{ Target Type } & \multicolumn{4}{|c|}{ Filler Task Difficulty } & & \\
\hline & \multicolumn{2}{|c|}{ Easy } & \multicolumn{2}{|c|}{ Hard } & \multicolumn{2}{|c|}{ Difference } \\
\hline & RT & $\% \mathrm{E}$ & RT & $\% \mathrm{E}$ & RT & $\% \mathrm{E}$ \\
\hline Easy & 480 & 0.6 & 494 & 1.1 & 14 & 0.5 \\
\hline Hard & 610 & 3.5 & 637 & 3.3 & 27 & -0.2 \\
\hline Difference & 130 & 2.9 & 143 & 2.2 & & \\
\hline
\end{tabular}

Table 4

Mean Lexical Decision Latencies (RTs, in Milliseconds) and Percent Error Rates (\% E) in Experiment 2

\begin{tabular}{|c|c|c|c|c|c|c|}
\hline \multirow[b]{3}{*}{ Target Type } & \multicolumn{4}{|c|}{ Filler Task Difficulty } & & \\
\hline & \multicolumn{2}{|c|}{ Easy } & \multicolumn{2}{|c|}{ Hard } & \multicolumn{2}{|c|}{ Difference } \\
\hline & RT & $\% \mathrm{E}$ & RT & $\% \mathrm{E}$ & RT & $\% \mathrm{E}$ \\
\hline \multicolumn{7}{|l|}{ Words } \\
\hline Easy & 488 & 3.8 & 517 & 3.8 & 29 & 0.0 \\
\hline Hard & 645 & 18.1 & 668 & 15.8 & 23 & -2.3 \\
\hline Difference & 157 & 14.3 & 151 & 12.0 & & \\
\hline \multicolumn{7}{|l|}{ Nonwords } \\
\hline Easy & 509 & 2.3 & 566 & 2.5 & 57 & 0.2 \\
\hline Hard & 665 & 7.5 & 725 & 14.1 & 60 & 6.6 \\
\hline Difference & 156 & 5.2 & 159 & 11.6 & & \\
\hline
\end{tabular}

Lexical decision: "no" response. A $2 \times 2$ ANOVA of nonword decision latency revealed significant main effects of both target task difficulty $\left[F_{1}(1,31)=258.22\right.$, $\left.M S_{\mathrm{e}}=3,070.49 ; F_{2}(1,78)=391.34, M S_{\mathrm{e}}=2,373.97\right]$ and filler task (reading aloud) difficulty $\left[F_{1}(1,31)=32.77\right.$, $\left.M S_{\mathrm{e}}=3,338.08 ; F_{2}(1,78)=70.32, M S_{\mathrm{e}}=1,524.76\right]$. These two effects did not interact $\left[F_{1}(1,31)<1.0 ; F_{2}(1,78)<\right.$ $1.0]$. Once again, the speed with which "no" responses were made was dependent on both the characteristics of the nonwords and the characteristics of the reading aloud items in the experiment.

In the analysis of nonword decision errors, the main effect of target task difficulty was significant $\left[F_{1}(1,31)=\right.$ $\left.20.42, M S_{\mathrm{e}}=109.52 ; F_{2}(1,78)=59.73, M S_{\mathrm{e}}=1.19\right]$, as was the main effect of filler task difficulty $\left[F_{1}(1,31)=\right.$ $\left.7.37, M S_{\mathrm{e}}=49.04 ; F_{2}(1,78)=10.31, M S_{\mathrm{e}}=1.12\right]$. The interaction effect was also significant $\left[F_{1}(1,31)=11.93\right.$, $\left.M S_{\mathrm{e}}=27.51 ; F_{2}(1,78)=9.38, M S_{\mathrm{e}}=1.12\right]$.

\section{Discussion of Experiment 2}

Like the effects for Experiment 1, those observed for Experiment 2 are clear. When reading aloud and visual lexical decision trials were presented in alternation, blocking effects across tasks emerged. The difficulty of reading aloud trials affected visual lexical decision latencies for both "yes" and "no" responses; lexical decisions were slower in the presence of difficult reading aloud trials than in the presence of easy reading aloud trials. Similarly, the difficulty of visual lexical decision trials affected reading aloud latency: Hard lexical decision trials induced slower reading aloud performance than did easy lexical decision trials. These blocking effects emerged on top of any switch costs that may have been induced by the alternating task situation that characterized this experiment. Although blocking effects have been reported across input domains (Lupker et al., 2000), we are unaware of any other demonstration of blocking effects arising across output domains.

\section{GENERAL DISCUSSION}

In the experiments reported here, we examined whether the blocking effects in the reading aloud task reported by Lupker et al. (1997) and Taylor and Lupker (2001) are observed in the visual lexical decision task, and indeed, in the 
situation in which reading aloud and visual lexical decision tasks are performed alternately in a single experiment. The answers to these questions were unambiguous. Both "yes" and "no" responses of the visual lexical decision task showed the same pattern of blocking effects as has been found in the reading aloud task. More importantly, there was an effect of filler task difficulty when different tasks were mixed within a single experiment: Reading aloud responses were influenced by the characteristics of lexical decision items, and lexical decision responses were influenced by the characteristics of reading aloud items.

At one level, these findings contribute to a growing body of empirical data that demonstrates the generality of blocking effects. Blocking effects generalize to a number of different input types-the written word, pictures, and sums-and also to different output types, including spoken words and button presses. Lupker et al. (2000) demonstrated that blocking effects arise when different input types are presented within a single experiment, while holding output type constant. Conversely, we have observed here that blocking effects are seen when different output types are presented in a single experiment, while holding input type constant. This body of findings has clear methodological implications: Context effects exert themselves in a very powerful way across a whole range of experimental tasks.

We believe that our data indicate that whatever mechanism is proposed to account for blocking effects, it must operate at a level of processing common to reading aloud and visual lexical decision tasks. We monitor our performance, irrespective of task, then tune what appears to be a single strategic mechanism that affects performance on both tasks. It is for this reason, we suggest, that the difficulty of one task influences (and is influenced by) the difficulty of another task.

What, then, of Lupker and colleagues' flexible timequality criterion? Clearly, if the concept of adjustable thresholds (for time and quality) that control information flow between levels of processing is to provide a viable account of the effects we have observed, then these adjustable thresholds cannot be applied at a stage of processing relevant to the computation of articulatory commands, because visual lexical decision does not engage this stage of processing. Rather, such thresholds must operate at a level of processing common to the reading aloud and visual lexical decision tasks - perhaps a processing module at which motor instructions for action (whether this action be speaking or pressing a button) are activated. According to this theory, activations from the reading aloud and visual lexical decision tasks would cascade into a general module for motor planning. In this module the activations would stay until the correct combination of values for time and quality were reached-at which time information would be passed to a motor execution module.

How, though, would criterial values of time and quality be established? Clearly, since reading aloud and lexical decision tasks were reciprocally influential in our experiment, the adopted values of time and quality would have to be based on the nature of all stimuli in the experiment, irrespective of task. Does a task-independent time-quality criterion, however, allow for intrinsic latency differences between reading aloud and lexical decision responses? Certainly in our experiment (and perhaps in general), lexical decision responses, particularly the "no" response, are slower than reading aloud responses, and one wonders whether this observation would be feasible in a response system incorporating a single time-quality criterion controlling reading aloud and lexical decision responding. Taylor and Lupker (2001) have argued, of course, that stimulus difficulty effects in mixed blocks can be preserved using time and quality criteria in combination, though this remains to be tested in a computational implementation. Our cross-task blocking observations pose similar challenges for the time-quality account; and additional theoretical and computational work must be achieved before Lupker and colleagues' flexible time- quality criterion theory can be evaluated in this cross-task context.

An alternative conceptualization of blocking effects recently proposed by Kello and Plaut $(2000,2003)$ is that blocking effects are due not to an adjustable thresholding mechanism operating in a single processing module, but rather to alterations in the strength of processing across an entire processing system. In the models of reading aloud envisaged and implemented by Kello and Plaut (2000, 2003), strength of processing is governed by a multiplicative scaling parameter that controls the amount by which unit activations are updated on each processing cycle of the model (it is important to note that strength of processing is a standard parameter not only in distributed connectionist models, but in activation models in generalfor example, the DRC model of Coltheart et al., 2001). Although Kello and Plaut $(2000,2003)$ termed this concept "input gain," it does not apply just to the strength of input from the stimulus to the processing system; instead, it deals with the strength of the input to each processing unit in the system. The larger the value of the input gain parameter, the more rapidly each individual unit will respond to a change in the input it receives from other units.

One can therefore envisage a situation in which subjects alter the strength of processing in response to stimulus demands. In pure blocks of easy items, subjects turn up the gain (i.e., they accept less information for greater gainthey don't require themselves to be certain of the input for increases in activation), resulting in shorter latencies. In pure blocks of hard items, subjects need to be more conservative: Gain is set at a lower level, leading to longer RTs. In mixed blocks of easy and hard items, gain is set at an intermediate level, resulting in RT homogenization. Indeed, using this approach, Kello and Plaut (2003) accomplished a simulation of blocking effects on reading aloud similar to those reported in Experiment $1 \mathrm{~A}$ and by Lupker et al. (1997) in two connectionist simulations of reading aloud.

Kello and Plaut $(2000,2003)$ conceptualized input gain within a model of reading aloud, but this is a general feature of activation models and could be employed across a 
range of performance tasks (e.g., visual lexical decision). In fact, blocking effects that generalize across tasks in a single experiment (as we've observed here) could be realized by modifications to the input gain parameter, as long as these tasks share at least one processing component. Reading aloud and visual lexical decision tasks share a number of processing components, and have been simulated within a single model of reading (i.e., Coltheart et al.'s, 2001, DRC model). As such, any alteration to the input gain parameter will have an effect on performance in both tasks. Because reading aloud and visual lexical decision were reciprocally influential in our experiment, we suggest that the value of the input gain parameter would be set on the basis of the nature of all stimuli in the experiment, irrespective of task.

It is important to realize that each of these ideas about the nature of blocking effects must be viewed within the context of a theory of word processing - and we suggest cautiously that one aspect of the data we have reported may be difficult to reconcile with Kello and Plaut's (2000, 2003) conceptualization of input gain. Consider, for example, responding to easy lexical decision items in Experiment 2 . In order to explain our observation that the latencies for these items are shorter when they are mixed with easy reading aloud items (pure block) than when they are mixed with hard reading aloud items (mixed block), the assumption would have to be that the gain parameter was set higher in the former case than in the latter. Because turning up the gain results in greater activation, this allows participants to respond "yes" in visual lexical decision more quickly in the pure blocks of easy items than in the mixed blocks, which is exactly the pattern we observed. What influence, however, would gain increase be predicted to have on "no" responding in the visual lexical decision task? Kello and Plaut $(2000,2003)$ have not discussed how visual lexical decision, and in particular the "no" response, might be accomplished in their connectionist implementations. However, a popular way of conceptualizing rejection in the decision task, expressed in the DRC model (Coltheart et al., 2001), is that increases in activation (e.g., due to a large number of neighbors or to pseudohomophony) lead to longer rejection latencies. If this model of the "no" response is adopted, then increases in input gain (and, therefore, activation) in the pure easy block situations will result in longer rejection latencies-a prediction exactly opposite to the pattern of rejection latencies observed.

The same problem holds true when one considers responding to the hard lexical decision items. When hard lexical decision items are mixed with easy reading aloud items, gain is turned up relative to situations in which hard lexical decision items are mixed with hard reading aloud items. Turning up the gain (increasing the activation) leads to shorter "yes" latencies for hard lexical decision items in mixed blocks than in pure blocks, exactly as was observed in the experiment. However, this increase in activation in the mixed block situation will also lead to longer rejection latencies for nonwords, and this pattern is exactly the opposite of what we observed.
We are not suggesting that these data falsify an input gain account of blocking effects. However, we are suggesting that these data pose a difficult problem for the input gain account in the context of current theories of visual lexical decision (e.g., the conceptualization of visual lexical decision proposed in the DRC model; Coltheart et al., 2001). We suggest, in light of the empirical observations reported here, that if the input gain account is to advance further as a general account of strategic processing, then it will be necessary to reconcile it with an account of visual lexical decision.

\section{CONCLUSIONS}

In this article, we have extended the original findings of Lupker et al. (1997) — that reading aloud latencies for easy and hard items become more homogeneous under mixedblock presentation relative to pure block presentation-to the visual lexical decision task and, more importantly, to the situation in which visual lexical decision and reading aloud trials are presented alternately in the same experiment. These findings lead us to conclude with some certainty that the RT homogenization effects seen in reading aloud are not a phenomenon particular to the activation of articulatory information from the phonological code (Taylor \& Lupker, 2001). Rather, we believe that these effects must engage a more general mechanism-one that operates at a stage (or stages) of processing common to both visual lexical decision and reading aloud tasks. We have described two approaches to theorizing about the nature of this mechanism, and, although our data cannot adjudicate between these approaches, we believe that they do place important constraints on each that will contribute to theorizing in the future.

\section{REFERENCES}

Batyen, R. H., Piepenbrock, R., \& van Rijn, H. (1993). The CeleX lexical database (CD-ROM). Philadelphia: University of Pennsylvania, Linguistic Data Consortium.

Chateau, D., \& Lupker, S. J. (2003). Strategic effects in word naming: Examining the route emphasis versus time-criterion accounts. Journal of Experimental Psychology: Human Perception \& Performance, 29, 139-151.

Coltheart, M. (1978). Lexical access in simple reading tasks. In G.Underwood (Ed.), Strategies of information processing (pp. 151-216). London: Academic Press.

Coltheart, M., Rastle, K., Perry, C., Langdon, R, \& Ziegler, J. (2001). DRC: A dual route cascaded model of visual word recognition and reading aloud. Psychological Review, 108, 204-256.

GlanZer, M., \& Ehrenreich, S. L. (1979). Structure and search of the internal lexicon. Journal of Verbal Learning \& Verbal Behavior, 18, 381-398.

GLushKo, R. J. (1979). The organization and activation of orthographic knowledge in reading aloud. Journal of Experimental Psychology: Human Perception \& Performance, 5, 674-691.

Gordon, B. (1983). Lexical access and lexical decision: Mechanisms of frequency sensitivity. Journal of Verbal Learning \& Verbal Behavior, 22, 24-44.

Humphreys, G. W., \& Evett, L. J. (1985). Are there independent lexi$\mathrm{cal}$ and nonlexical routes in word processing? An evaluation of the dual-route theory of reading. Behavioral \& Brain Sciences, 8, 689-740.

Kello, C. T., \& Plaut, D. C. (2000). Strategic control in word reading: Evidence from speeded responding in the tempo-naming task. Jour- 
nal of Experimental Psychology: Learning, Memory, \& Cognition, 26, 719-750.

Kello, C. T., \& Plaut, D. C. (2003). Strategic control over rate of processing in word reading: A computational investigation. Journal of Memory \& Language, 48, 207-232.

Kinoshita, S., \& LUPKER, S. J. (2002). Effects of filler type in naming: Change in time criterion or attentional control of pathways? Memory \& Cognition, 30, 1277-1287.

Los, S. A. (1996). On the origin of mixing costs: Exploring information processing in pure and mixed blocks of trials. Acta Psychologica, 94, 145-188.

Los, S. A. (1999). Identifying stimuli of different perceptual categories in mixed blocks of trials: Evidence for cost in switching between computational processes. Journal of Experimental Psychology: Human Perception \& Performance, 25, 3-23.

LuPKeR, S. J., BRown, P., \& Colombo, L. (1997). Strategic control in a naming task: Changing routes or changing deadlines? Journal of Experimental Psychology: Learning, Memory, \& Cognition, 23, 570-590.

Lupker, S. J., Kinoshita, S., Tay lor, T. E., \& Coltheart, M. (2000, November). Is a time criterion used when naming pictures and computing sums? Paper presented at the 41 st annual meeting of the Psychonomic Society, New Orleans.

Merian, N. (2000). Modeling cognitive control in task-switching. Psychological Research, 63, 234-249.

Monsell, S., Patterson, K. E., Graham, A., Hughes, C. H., \& MilROY, R. (1992). Lexical and sub-lexical translation of spelling to sound: Strategic anticipation of lexical status. Journal of Experimental Psychology: Learning, Memory, \& Cognition, 18, 452-467.

Pechmann, T., Reetz, H., \& Zerbst, D. (1989). Kritik einer meßmethode: Zur Ungenauigkeit von Voice-key Messungen [Critique of a method of measurement: On the reliability of voice-key measurements]. Sprache \& Kognition, 8, 65-71.

Plaut, D. C., McClelland, J. L., Seidenberg, M. S., \& Patterson, K. (1996). Understanding normal and impaired word reading: Computational principles in quasi-regular domains. Psychological Review, 103, 56-115.

Rastle, K., \& Coltheart, M. (1999). Serial and strategic effects in reading aloud. Journal of Experimental Psychology: Human Perception \& Performance, 25, 482-503.

RAstLe, K., \& DAVIS, M. H. (2002). On the complexities of measuring naming. Journal of Experimental Psychology: Human Perception \& Performance, 28, 307-314.

Rastle, K., Harrington, J. M., \& Coltheart, M. (2002). 358,534 nonwords: The ARC nonword database. Quarterly Journal of Experimental Psychology, 55A, 1339-1362.

Rogers, R. D., \& Monsell, S. (1995). Costs of a predictable switch between simple cognitive tasks. Journal of Experimental Psychology: General, 124, 207-231.

SaKuma, N., Fushimi, T., \& TATsumi, I. (1997). Measurement of nam- ing latency of Kana characters and words based on speech analysis: Manner of articulation of a word-initial phoneme considerably affects naming latency. Japanese Journal of Neuropsychology, 13, 126-136. Strayer, D. L., \& Kramer, A. F. (1994a). Strategies and automaticity: I. Basic findings and conceptual framework. Journal of Experimental Psychology: Learning, Memory, \& Cognition, 20, 318-341.

Strayer, D. L., \& Kramer, A. F. (1994b). Strategies and automaticity: II. Dynamic aspects of strategy adjustment. Journal of Experimental Psychology: Learning, Memory, \& Cognition, 20, 342-365.

TAYlor, T. E., \& LUPKER, S. J. (2001). Sequential effects in naming: A time-criterion account. Journal of Experimental Psychology: Learning, Memory, \& Cognition, 27, 117-138.

Zevin, J. D., \& Balota, D. A. (2000). Priming and attentional control of lexical and sublexical pathways during naming. Journal of Experimental Psychology: Learning, Memory, \& Cognition, 26, 121-135.

\section{NOTES}

1. In these studies of visual lexical decision, the pattern of RT homogenization effect was asymmetric (an increase in decision time was observed for the easy, high-frequency items, but a decrease in decision time was not observed for the hard, low-frequency items). Although this pattern of data is often associated with mixing-cost theories of strategic processing (see, e.g., Los, 1999), that interpretation is unlikely to be correct here: In this instance, the mixed-block situation (i.e., low-frequency and high-frequency words) cannot be thought of in terms of a switch between computationally different processes.

2. Recently, a number of authors (e.g., Pechmann, Reetz, \& Zerbst, 1989; Sakuma, Fushimi, \& Tatsumi, 1997) have confirmed not only that voice key measurements can be highly inaccurate, but, critically, that voice key error can interact with linguistic manipulations, leading to changes in the magnitude and direction of observed effects (Rastle \& Davis, 2002). Although we used a voice key to detect acoustic onset here, we followed the recommendations of Rastle and Davis to ensure that any error associated with the voice key did not vary systematically across conditions - that is, our by-items analysis consisted of a repeated-item comparison, and our by-participants analysis compared words with shared onsets (i.e., all phonemes prior to the vowel).

3. It is important to note that this is a different analysis from that presented in Experiment 1, in which an interaction was expected. In that analysis, we examined target difficulty (easy vs. hard) and block type (pure vs. mixed). It is, of course, possible to replot the data from Experiment 2 (in which mixed conditions contain, for example, easy reading aloud items and hard lexical decision items) in the same way, and an interaction would be expected. We chose to analyze the data from Experiment 2 in terms of target type and filler type because, unlike in Experiment 1 , the mixed condition actually comprised two separate blocks (i.e., easy reading aloud with hard lexical decision items and hard reading aloud with easy lexical decision items). 


\section{APPENDIX}

\section{Easy Items Used in Reading Aloud}

beach, drink, force, horse, large, might, night, peace, plant, press, shape, small, sound, stage, stock, thick, trade, cheap, while, claim, crime, march, plain, shirt, smell, stand, stone, taste, pride, right, brain, chair, leave, quick, sight, space, think, dream, faith, shall, birth, dress, found, house, least, mouth, noise, place, point, price, sharp, smile, south, start, stuff, thing, train, check, white, cloth, cross, match, plane, shock, smoke, steel, store, tight, proud, range, birth, chest, light, quite, since, speed, third, drive, fight, share

\section{Hard Items Used in Reading Aloud}

bluzz, bryle, chudd, clatt, cludd, crurk, drent, drutt, flemp, frerb, glewt, glong, glyme, pherb, phipe, phlub, phrim, phruv, plarb, ploob, plype, praim, praut, skurb, snyme, splom, splug, thean, thran, vewth, breph, crarf, drimb, flerp, pherp, phroz, shrif, thrac, plizz, phurg, bluce, brulk, chazz, clarf, cloob, crurg, drelf, drith, fladd, fralp, glerg, glodd, glurn, pheem, phert, phleg, phrez, phrup, plaff, plazz, plurg, praif, praul, skarb, snudd, sploc, sploz, tharb, thrag, veece, braff, crarc, drich, flene, pherf, phron, sherg, thisc, glirr, phult

\section{Easy Items Used in Visual Lexical Decision}

WORDS: game, book, full, year, like, case, best, made, take, none, land, hard, near, gone, look, head, want, came, done, line, love, must, deal, bank, hall, dear, last, come, hand, seen, room, here, good, side, name, lord, road, work, nice, long

NONWORDS: sesc, jalv, kruf, kuiv, ceeb, kooc, beve, jebb, oagg, yubb, giep, wuic, jauc, gwom, twuz, anck, zaln, geiv, zagg, teif, knal, tege, nieb, wiem, fruf, scic, kref, tyln, dwef, wumn, zauk, dwof, kulc, zorf, geup, tuib, mymb, yaup, kylk, komf

\section{Hard Items Used in Visual Lexical Decision}

WORDS: hoax, glib, drip, wrap, rein, thud, grub, smug, gulp, fuzz, twig, flux, yolk, chef, chub, germ, scum, buzz, sect, quay, thai, gnat, fret, wham, noun, lisp, quip, smut, yelp, fete, helm, purr, ooze, hymn, crib, feud, fern, thug, swum, snub

NONWORDS: hase, holl, lage, mape, bage, sace, mose, jine, pook, fass, lote, reat, beal, doke, roke, runk, hine, yill, leat, pame, gake, bape, selt, pell, dack, rame, wint, dile, pank, gare, kile, wone, kine, cass, tean, pake, fent, nove, jare, lole 